\title{
Sürdürülebilir Betonlu Betonarme Yüksek Kirişlerin Yapısal Optimizasyonu
}

\author{
'İlyas SARIBAŞ \\ ${ }^{1}$ Alparslan Türkeş Science and Technology University, Civil Engineering Department, \\ Sarıçam, Adana, Turkey, E-mail: isaribas@ atu.edu.tr
}

\section{Özet:}

Üretiminde, doğal betona göre daha düşük enerji tüketen ve daha az karbon gazı salınımı sağlayan beton yeşil, çevreci veya sürdürülebilir beton olarak isimlendirmektedir. Sürdürülebilir beton üretiminde dönüştürülerek ekonomiye kazandırılmış atık beton malzemeleri kullanılmaktadır. Atık betonların dönüştürülmesiyle elde edilen malzemelerden birisi de geri dönüşümlü agregadır. Yapılan kapsamlı deneysel ve analitik çalışmalarda bu agreganın belirli koşullar altında doğal agregaya alternatif bir ürün olabileceği belirtilmiştir. Bu çalışmada, dört farklı oranda geri dönüşümlü agrega içerdiği kabul edilen yüksek kirişlerin tasarımı "isoline topology design" eşdeğer-çizgi topoloji tasarım metoduna göre yapılmıştır. Elde edilen sonuçlar doğal agregalı yüksek kirişlerin tasarım sonuçları ile karşılaştırılmıştır. Bu sonuçlara göre; \%25 ve \%50 oranında geri dönüşümlü agrega içeren yüksek kirişlerin tasarım sonuçların doğal agregalı kirişlerin tasarım sonuçlarına benzediği görülmüştür. Yüksek kirişlerdeki geri dönüşümlü agrega oranı arttıkça (\%50 üstü) bu kirişlerin tasarım sonuçlarının doğal agregalı kirişlerin tasarım sonuçlarından hızla uzaklaştığı belirlenmiştir.

Anahtar kelimeler: Doğal agrega, Geri dönüşümlü agrega, Sürdürülebilir beton, Topoloji optimizasyonu, Yapısal optimizasyon, Yüksek kiriş

\section{Structural Optimization of Reinforced Sustainable Concrete Deep Beams}

\begin{abstract}
:
Green, environmentally friendly, or sustainable concrete is defined as concrete containing waste materials in its components and does not cause environmental problems in its production. In the production of sustainable concrete, recycled waste concrete materials are used. One of the materials obtained by recycling waste concrete is recycled concrete aggregate. It has been stated in the literature that this aggregate may be an alternative product to natural aggregate under certain conditions. In this study, the structural optimization of deep beams assumed to be produced with recycled concrete aggregates in four different ratios $(25 \%, 50 \%, 75 \%, 100 \%)$ was carried out by the isoline topology design method. The structural optimization results of sustainable concrete deep beams were compared with the conventional concrete deep beam results. As a result of the optimization process, it was observed that the structural optimization behavior of deep beams containing $25 \%$ and $50 \%$ recycled concrete aggregates was similar to the conventional concrete deep beams. As the recycled concrete aggregate ratio increased (over 50\%) in sustainable concrete, the structural optimization behavior of these beams deviated rapidly from the structural optimization result of the conventional concrete deep beam.
\end{abstract}

Keywords: Isoline topology design, Natural aggregate, Recycled concrete aggregate, Sustainable concrete, Topology optimization, Structural optimization, Deep beam 


\section{Giriş}

İnşaat sektörünün ana malzemelerinden olan beton sınırlı kullanım ömrüne sahiptir. Doğal veya yapay etkenlerle ömrünü dolduran beton, atık haline gelmektedir. Gelişmiş ve gelişmekte olan ülkelerde atık betonların miktarı, artan kentsel dönüşüm faaliyetleri ve/veya meydana gelen doğal afetler sonucunda günden güne artmaktadır. Çevreye, topluma ve ekonomiye direkt veya dolaylı yollardan zarar veren atık betonların ortadan kaldırılması için yapılan çalışmalar son yıllarda hız kazanmıştır. Geri dönüşüm, atık betonların bertaraf edilmesinde kullanılan etkili yöntemlerin birisidir. $\mathrm{Bu}$ yöntemle atık betonlar dönüştürülerek geri dönüşümlü agrega (GDA) haline getirilmektedir. Geri dönüşümlü agregaların doğal agregalara alternatif bir ürün olabileceği fikrinin bilimsel çalışmalarla desteklenmesiyle GDA'ların kullanım alanı günden güne artmaktadır. Ayrıca, bazı uluslararası yönetmeliklerde GDA'ların belirli malzeme koşullarını sağlaması durumunda doğal agregalara alternatif bir ürün olduğu belirtilmiştir [1-3].

Betonarme ve prefabrik yapılarda Bernoulli-Navier hipotezinin geçerli olmadığı, geometrik ve statik olarak süreksiz olan bölgeler D (Disturbed, Discontinuous) bölgeleri olarak isimlendirilmektedir (Şekil 1). D bölgelerinin tasarımında kullanılan yöntemlerden birisi Ritter [4] ve Mörsch [5-6] tarafından önerilen çubuk analojisi metodudur (strut and tie method; STM). Çubuk analojisi metodu D bölgelerinin tasarımı için basit bir yöntem olarak görülse de bu yöntemin en önemli eksikliği iterasyon yapma güçlüğüdür. Yapıların, ekonomik etkin ve yapısal olarak güvenli tasarlanması yapı mühendislerinin temel hedeflerindendir. Yapıların tasarımında, mühendislerin temel hedeflerine ulaşmasına katkı saplayacak yöntemlerden birisi yapısal optimizasyon metodudur [7-13]. Bu metotla yapısal elemanlar ekonomik etkin ve yapısal olarak güvenli bir şekilde tasarlanabilmektedir. Ayrıca bu yöntem, çubuk analojisi metodundaki bazı zorlukları da devre dışı bırakmaktadır. Yapısal optimizasyon yöntemi üçe ayrılmaktadır. Bunlar: boyut, şekil ve topoloji optimizasyonudur. Topoloji optimizasyon yöntemi, yapısal optimizasyon yöntemlerinin en genel halidir. Çünkü bu yöntemde yapısal elemanların boyutları ve şekilleri manipüle edilmemektedir. Topoloji optimizasyon yönteminde yapısal elemanların tasarımı, matematiksel tabanlı veya deneme-yanılma tabanlı yöntemlerle yapılmaktadır. Bu çalışma kapsamında, denemeyanılma tabanlı, dijital performans metodu olan "Isoline Topology Design" (ITD) eşdeğerçizgi topoloji tasarım metodu kullanılmıştır [7-13]. Yapısal optimizasyonda malzeme kaldırma ve ekleme kritik rol oynamasına rağmen, bu yöntem malzeme kaldırma ve ekleme işlemini Von Misses gerilme yaklaşımı ile eşdeğer yüzeyleri veya çizgileri kullanarak kolayca yapabilmektedir. Yapısal optimizasyonda çokça kullanılan ITD metodu, geri dönüşüm agregası içeren betonarme elemanların veya geri dönüşüm agregası içeren beton elemanların yapısal optimizasyonunda henüz kullanılmamıştır. Bu çalışma kapsamında, dört farklı oranda geri dönüşümlü agrega içerdiği kabul edilen yüksek kirişlerin tasarımı ITD metoduna göre yapılmıştır. Elde edilen sonuçlar doğal agregalı yüksek kirişlerin tasarım sonuçları ile karşılaştırılmıştır.

\section{Yüksek Kirişlerin Malzeme Özellikleri}

Bu çalışma kapsamında analizi yapılacak olan yüksek kirişlerin beton özelliğini temsil eden, doğal beton (DB), sırasıla \%25, \%50, \%75 ve \%100 oranında GDA içeren sürdürülebilir beton (SB) (SB25, SB50, SB75, SB100) olacak şekilde 5 farklı beton türü dikkate alınmıştır. Yapısal 
elemanların tasarımında kullanılan beton parametreleri modifiye Hognestad [14-15] modelinden elde edilmiştir. Betonarme çeliği için B420C donatı çeliği kullanılmıştır [16]. Betonlar ve donatı çeliğine ait veriler Tablo 1'de verilmiştir. Literatürdeki çalışmalarda, GDA içeren betonların birim hacim ağırlıklarının $\left(\rho_{c}\right)$ genellikle DB'den daha düşük olduğu belirtilmiştir [1-3]. Bu nedenle, doğal ve GDA içeren betonlar için farklı birim hacim ağırlıkları dikkate alınmıştır (Tablo 1).

Tablo 1. Beton ve donatiya ait karakteristik veriler

\begin{tabular}{lcccccccccc}
\hline $\begin{array}{l}\text { Yüksek kiriş } \\
(\mathrm{yk})\end{array}$ & $\begin{array}{c}f_{c} \\
(\mathrm{MPa})\end{array}$ & $\begin{array}{c}f_{c t} \\
(\mathrm{MPa})\end{array}$ & $\begin{array}{c}E_{c} \\
(\mathrm{MPa})\end{array}$ & $\begin{array}{c}\rho_{c} \\
\left(\mathrm{~kg} / \mathrm{m}^{3}\right)\end{array}$ & $\varepsilon_{\mathrm{co}}$ & $\begin{array}{c}f_{s y} \\
(M P a)\end{array}$ & $\begin{array}{c}E_{s} \\
(\mathrm{GPa} a)\end{array}$ & $\begin{array}{c}\rho_{s} \\
\left(\mathrm{~kg} / \mathrm{m}^{3}\right)\end{array}$ & $k_{l}$ & $k$ \\
\hline DB-yk & 34.0 & 2.041 & 28320 & 2400 & 0.00240 & 420 & 200 & 7850 & 4.81 & 0.68 \\
\hline SB25-yk & 32.3 & 1.989 & 26795 & 2300 & 0.00241 & 420 & 200 & 7850 & 5.05 & 0.68 \\
\hline SB50-yk & 27.2 & 1.825 & 23941 & 2300 & 0.00227 & 420 & 200 & 7850 & 5.34 & 0.64 \\
\hline SB75-yk & 25.5 & 1.767 & 22651 & 2300 & 0.00225 & 420 & 200 & 7850 & 5.49 & 0.62 \\
\hline SB100-yk & 23.8 & 1.707 & 21438 & 2300 & 0.00222 & 420 & 200 & 7850 & 5.64 & 0.60 \\
\hline
\end{tabular}

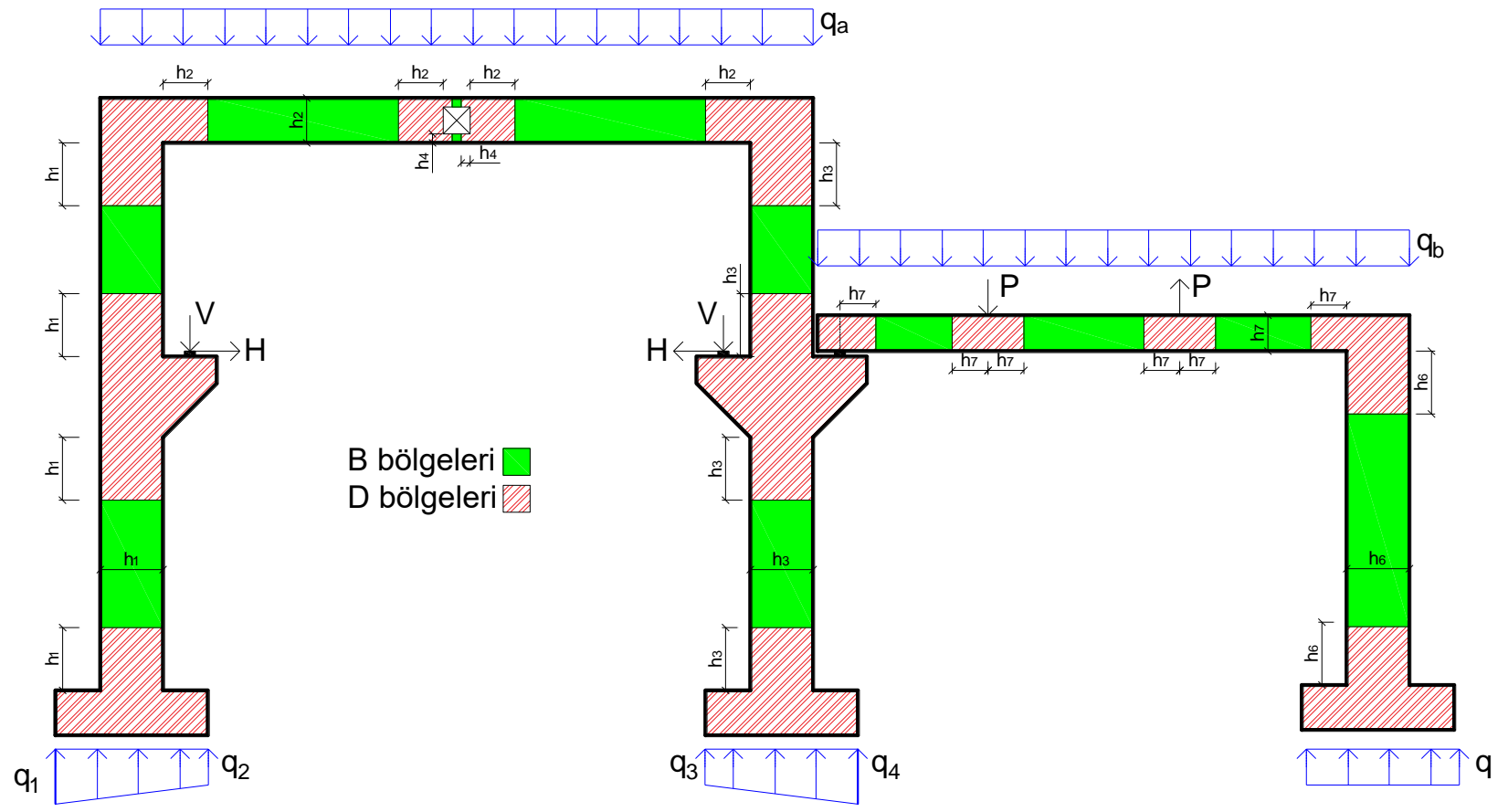

Şekil 1. Betonarme çerçevede B ve D bölgeleri [19]

\section{3. “Isoline Topology Design” Eşdeğerçizgi Topoloji Tasarım Metodu}

Yapısal tasarımda (çubuk analojisi metodunda olduğu gibi) mühendisin bilgi ve tecrübesi ön plandadır. Ancak, son zamanlarda bu durum yapısal tasarım için geliştirilen yenilikçi yöntemlerle değişmektedir [17]. Bu yöntemlerden birisi de ITD metodudur. Bu çalışmada, iteratif yeniden dağılım algoritması kullanan ITD (liteITD) metoduyla yüksek kirişlerin yapısal optimizasyon davranışı kapsamlı olarak araştırılmıştır [7-13]. Bu yöntemde kullanılan temel bağıntılar Denklem 1-8' de verilmiştir. Bu denklemlerdeki terimler sembol listesinde detaylı olarak açıklanmıştır. ITD metodunda minimum kıstas (kriter) seviyesi (Şekil 2) Denklem 1 ile, yapısal elemanların rijitlik 
matrisi Denklem 2 ile, kıstas (kriter) değerleri Denklem 3 ve 4'le, Von Misses gerilme dağılımında olduğu gibi tasarım kriteri Denklem 5 ile, minimum hacim değişim limiti Denklem 6 ile hesaplanmaktadır. Yapısal optimizasyonda önemli parametrelerden olan ve Dewhurst [18] tarafından önerilen optimallik (en uygunluk) kriterleri Denklem 7 ve 8 ile hesaplanmaktadır. Optimizasyon işleminde gerilme veya şekildeğiştirme tabanlı optimallik kriteri seçilebilmektedir. Bu seçimde ilgili kriterin yüksek hassasiyetle hesaplanması etkili olmaktadır. Çalışma kapsamında hesaplanan optimallik kriterleri $\left(k, k_{1}\right)$ Tablo 1'de verilmiştir.

$$
V_{i}=V_{o}+\left(V_{f}-V_{o}\right) \frac{i}{n_{i}}
$$

$K^{e}= \begin{cases}K_{I} & \text { if } \xi^{e}=1.0 \\ K_{o}=K_{I} \times F G_{R} & \text { if } \xi^{e}=0 \\ K_{B}=K_{I} \xi^{e}+K_{o}(1-\xi e) & \text { if } 0<\xi^{e}<1.0\end{cases}$

$\sigma_{i}=\frac{\sum_{e=1}^{N_{e}} \sigma_{e}^{i} \times V_{e}}{\sum_{e=1}^{N_{e}} V_{e}}$

$\sigma^{e}=\frac{\sum_{e=1}^{N_{i}} \sigma^{i}}{N_{i}}$

$\sigma=\sigma_{v M}=\sqrt{\sigma_{x}^{2}+\sigma_{y}^{2}-\sigma_{x} \sigma_{y}+3 \tau_{x y}^{2}}$

$\Delta V(\%)=\left[\frac{V_{i}}{V_{i-1}}-1\right] \times 100$

$k=\frac{\varepsilon_{s}^{*}}{\varepsilon_{c}^{*}}=\left[\frac{\rho_{s} E_{c}}{\rho_{c} E_{s}}\right]^{0.5}$

$k_{1}=\frac{\sigma_{s}^{*}}{\sigma_{c}^{*}}=\left[\frac{\rho_{s} E_{s}}{\rho_{c} E_{c}}\right]^{0.5}$ 


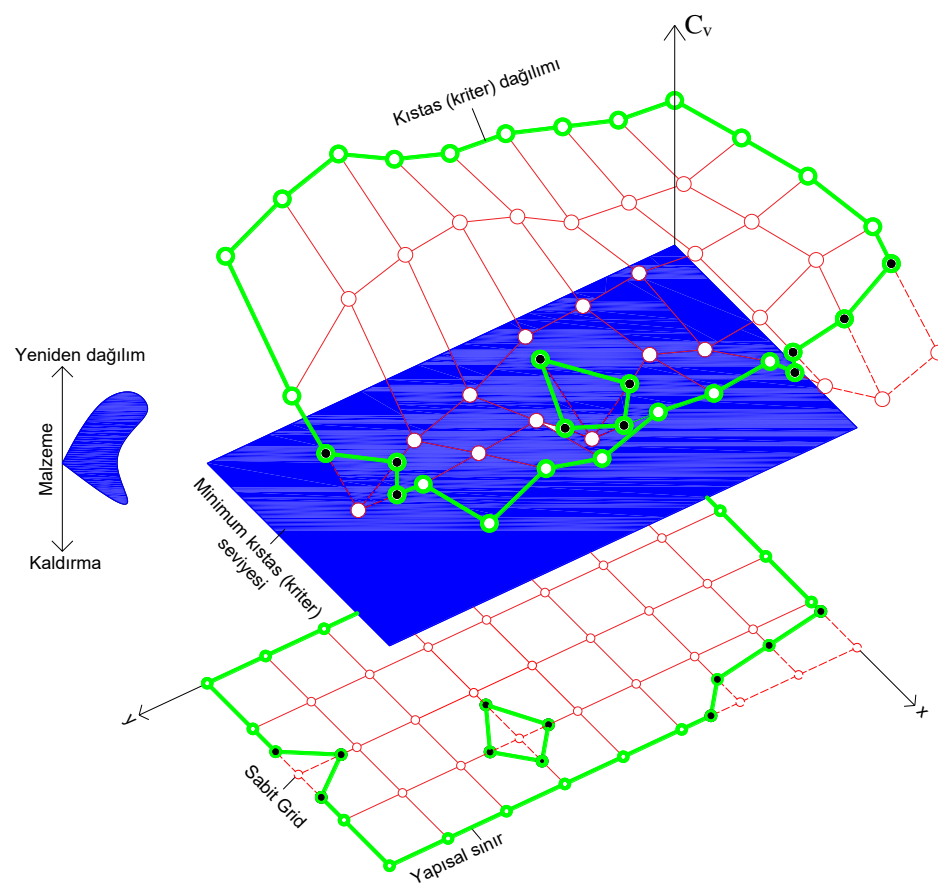

Şekil 2. Minimum kriter seviyesi, kriter dağılımı, malzeme ekleme/kaldırma ve yapısal sınır durumu [9-13]

\section{Yüksek Kirişlerin ITD Metoduna Göre Tasarımı}

Yüksek kirişlerin yapısal optimizasyon davranışının belirlenmesinde kullanılan ITD metodunda bu elemanların şekilleri ve boyutları manipüle edilmemektedir. Dolayısıyla tasarımı yapılacak elemanların boyutları ve şekli yapısal optimizasyonda birincil etken parametre değildir. Yapısal optimizasyonda, betonarme yüksek kirişlerin malzeme özellikleri Tablo 1'deki beton ve donatı parametreleri dikkate alınarak çoklu malzeme durumuna göre tanımlanmıştır. Ayrıca, betonarme kirişler $10 \times 10 \mathrm{~mm}$ boyutlarında sonlu elemanlara bölünmüş ve bu kirişlere tekil monotonik yük uygulanmıştır (Şekil 3b). Yüksek kirişlerin yük taşıma kapasitesini belirlemek için elle ve sonlu elemanlar yöntemi (FEM) ile yapılan hesaplardan kirişlerin kapasitesinin $530 \mathrm{kN}$ olduğu, çubuk analojisi metoduna (STM) göre yapılan hesapla $360 \mathrm{kN}$ olduğu belirlenmiştir (Şekil 3a). Buradan, STM metodunun kapasite hesabında çok güvenli tarafta kaldığı sonucu elde edilmektedir.
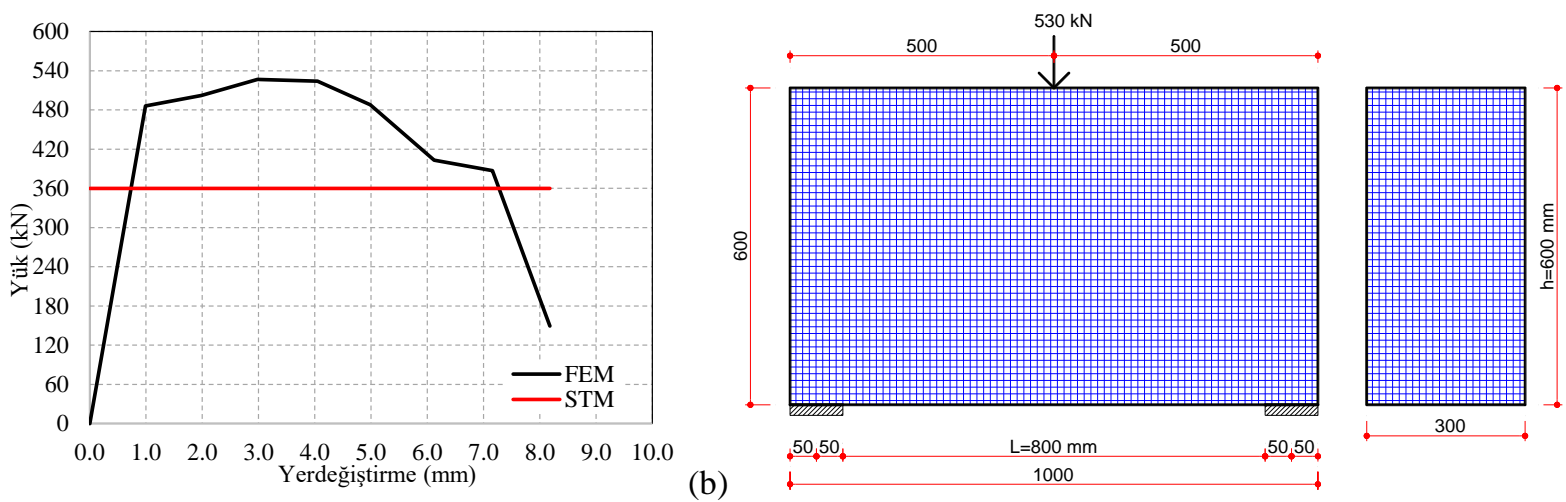

(a)

Şekil 3. (a) Yüksek kiriş kapasitesi, (b) kiriş boyutları, yük, mesnetlenme ve sonlu eleman özellikleri 
Yüksek kirişlerin ITD metodu kullanılarak elde edilen yapısal optimizasyon davranışları Şekil 4'te verilmiştir. Yapısal optimizasyon işlemi sırasında farklı iterasyonlarda DB-yk numunesinde meydana gelen değişimler Şekil 5'te verilmiştir. Tüm kirişlerin yapısal optimizasyon davranışları, 50 iterasyon, \%0.5 minimum hacim değişim oranı ve \%30 nesnel hacimsel oran koşulları dikkate alınarak elde edilmiştir. Elde edilen şekillerdeki kırmızı alanlar çekme bölgelerini, mavi alanlar basınç bölgelerini temsil etmektedir. Kirişlerin yapısal optimizasyon davranışları incelendiğinde, SB25-yk ve SB50-yk numuneleri DB-yk numunesiyle benzer davranış göstermiştir. Ancak, bu numunelerin çekme bölgelerinin mesnet'e yakın kısımlarında ki çekme ve basınç elemanlarında, malzeme yeniden dağılımı sırasında karakteristik beton özelliklerine bağlı olarak tutarsızlıkların olduğu tespit edilmiştir (Şekil $4 \mathrm{~b}-\mathrm{c}$ ). Tüm elemanlarda aynı tasarım parametreleri dikkate alınmasına rağmen, SB25-yk ve SB50-yk kirişlerinin mesnet bölgelerindeki ihmal edilebilir değişimin sebebi bu elemanların hem beton basınç dayanımı hem de elastisite modülü değerlerinin DB-yk numunesinden daha düşük olmasıdır.

(a)
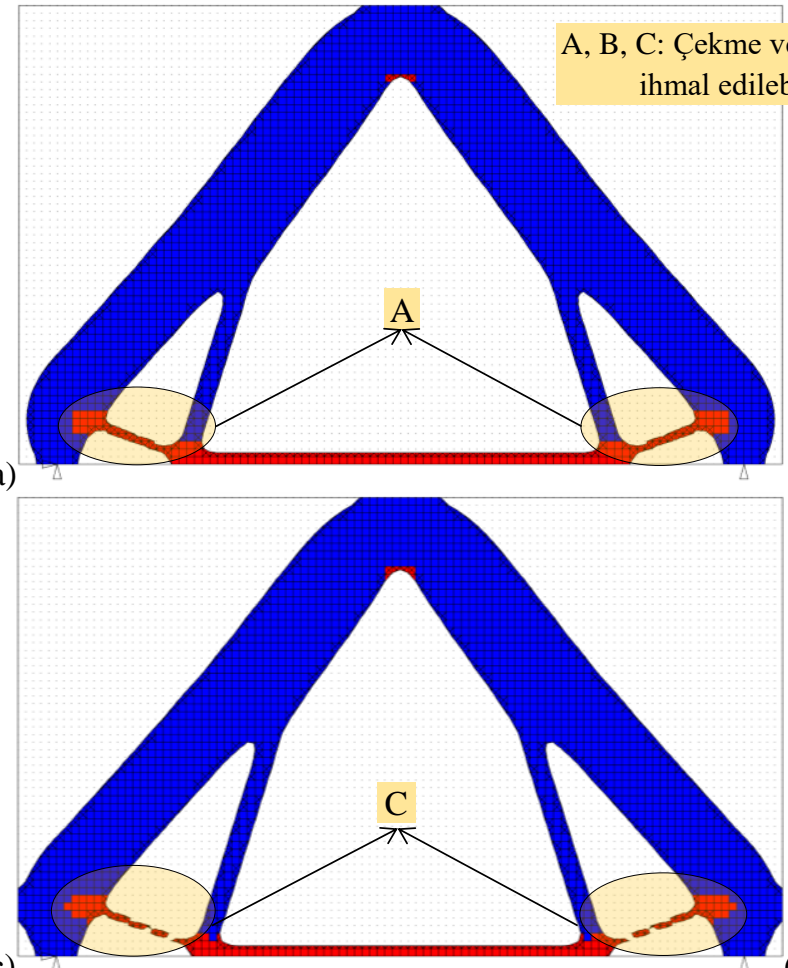

(c)

(d)

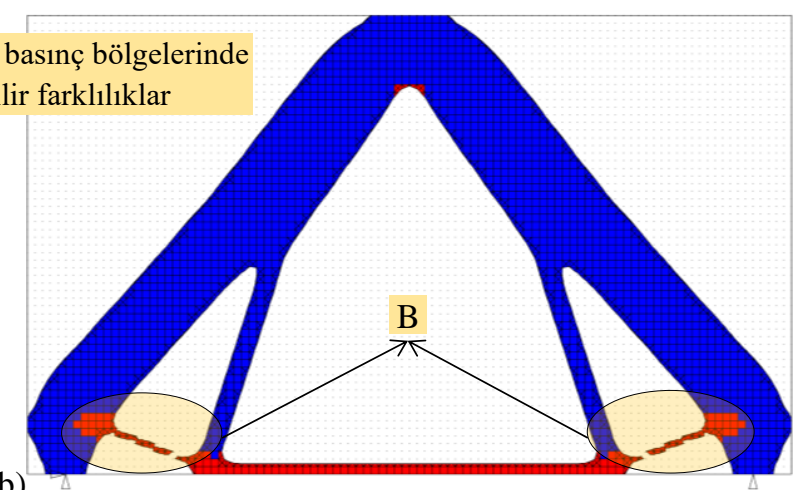

b)

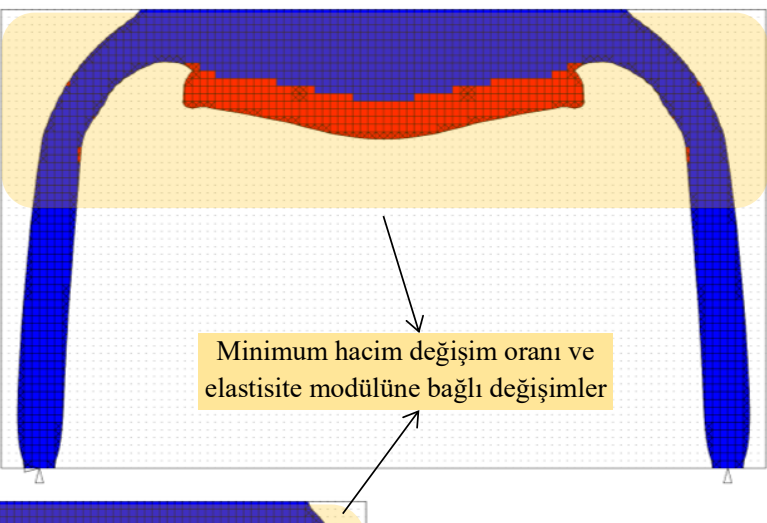

(e)

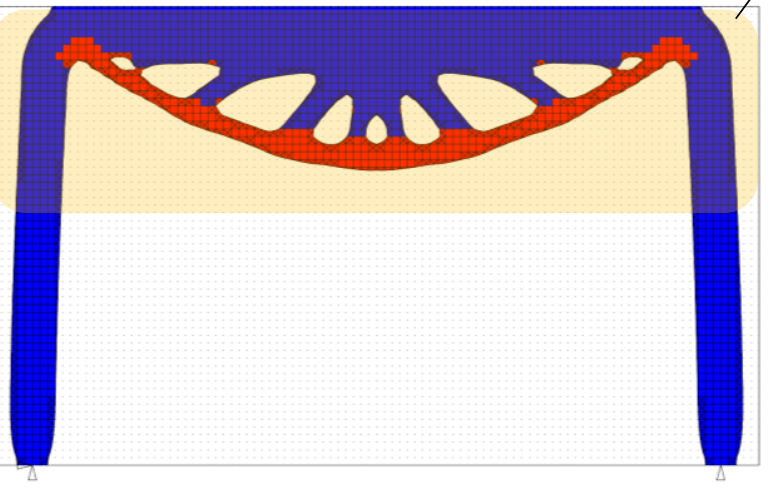

Şekil 4. Yapısal optimizasyon davranışları; (a) DB-yk, (b) SB25-yk, (c) SB50-yk, (d) SB75-yk, (e) SB100-yk 
DB-yk, SB25-yk ve SB50-yk numuneleri benzer yapısal optimizasyon davranışına sahip olmasına rağmen, SB75-yk ve SB100-yk numuneleri diğer üç numuneden tamamen farklı davranış göstermiştir. Bu farklılığın nedeni, sürdürülebilir beton içerisinde GDA oranı arttıkça düşen beton basınç dayanımı ve elastisite modülüdür. Ayrıca, düşük beton basınç dayanımı ve elastisite modülü kirişlerin monotonik yükler altındaki kapasitesini olumsuz etkilediği için, bu kirişler hacim değişim oranından daha fazla etkilenmektedirler. Yine sürdürülebilir betonlu yapısal elemanlardan yüksek oranda GDA içerenlerin (SB75-yk, SB100-yk) yapısal optimizasyonunda diğer elamanlara göre daha yüksek minimum hacim değişim oranı seçilmesi gerektiği tespit edilmiştir. Dolayısıyla, SB75-yk ve SB100-yk numunelerinin yapısal optimizasyon davranışının, aynı koşullarda DB-yk numunesine benzer olarak elde edilebilmesi için bu iki numunenin minimum hacim değişim oranının \%0.5'ten \%1'e çıkarılması gerekmektedir. Yine SB75-yk ve SB100-yk numunelerinin basınç bölgesi alanlarının diğer numunelerden daha az olmasına rağmen, çekme bölgesi alanlarının daha fazla olduğu Şekil 4d-e'den görülmektedir. Ayrıca, beton birim hacim ağırlıklarının yapısal optimizasyon davranışına etki etmediği belirlenmiştir.

(a)

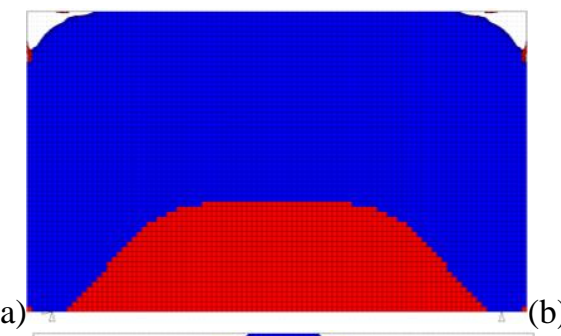

(d)

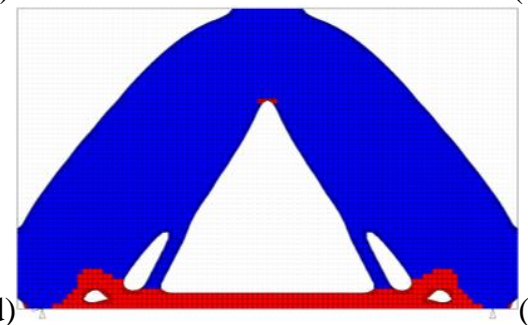

(g)

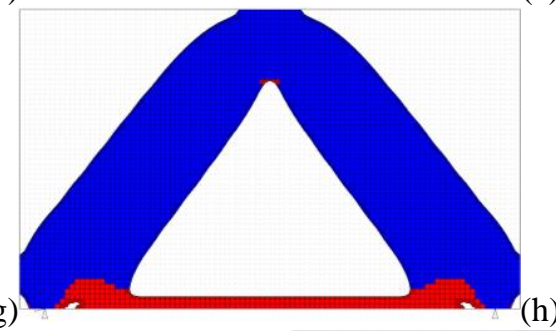

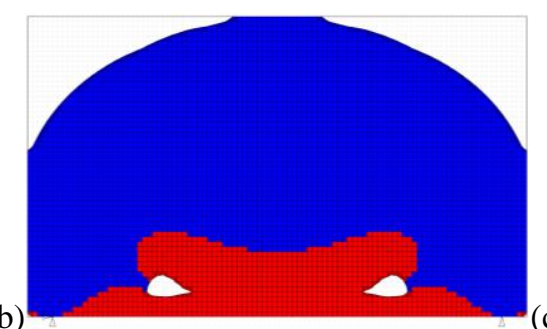

(c)

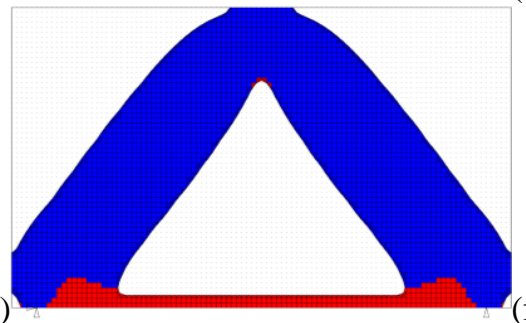

e)

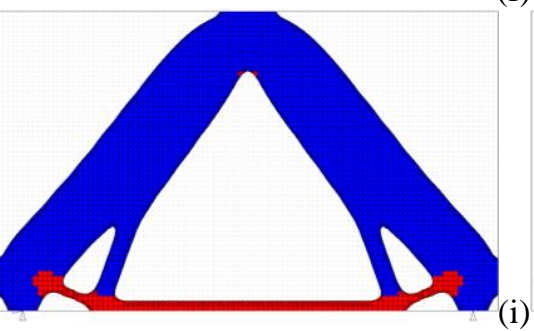

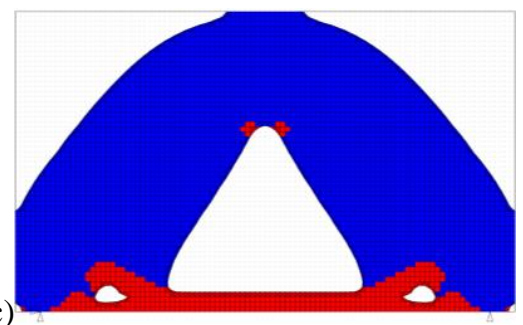

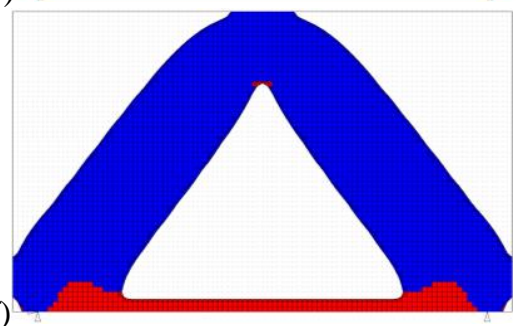

(f)

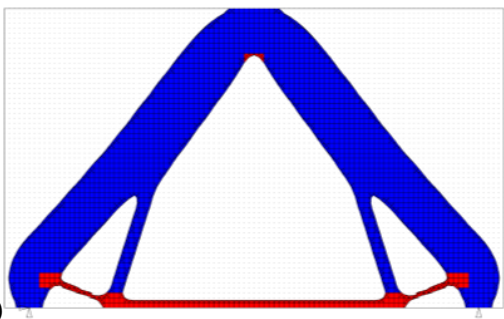

$(\mathrm{k})$
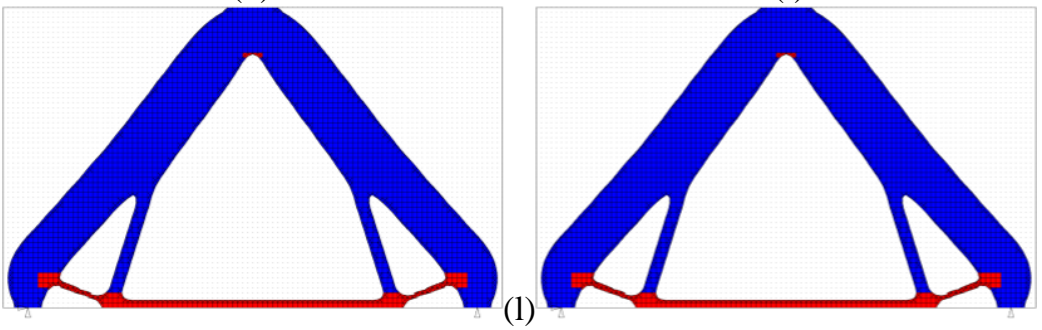

(1)

Şekil 5. Yapısal optimizasyon aşamaları; (a) 1. iterasyon, (b) 5. iterasyon, (c) 10. iterasyon, (d) 15. iterasyon, (e) 20. iterasyon, (f) 25. iterasyon, (g) 30. iterasyon, (h) 35. iterasyon, (i) 40. iterasyon, (k) 45. iterasyon, (l) optimize edilmiş yüksek kiriş 


\section{Sonuçlar}

Bu çalışmada farklı oranda sürdürülebilir beton içeren yüksek kirişlerin yapısal optimizasyon davranışı kapsamlı olarak araştırılmıştır. Elde edilen optimizasyon sonuçları DB'li yüksek kirişin sonuçları ile karşılaştırılmıştır. Yapılan karşılaştırmalardan aşağıdaki sonuçlar elde edilmiştir.

- Sürdürülebilir betonlu yüksek kirişlerin içerisindeki GDA oranı artıkça yapısal optimizasyonda minimum hacim değişim oranının arttırılması gerekmektedir.

- Beton birim hacim ağırlığının yapısal optimizasyon davranışına etki etmediği elde edilmiştir.

- ITD metodunun GDA oranının \%50 ve altında olduğu yapısal elemanların optimizasyon davranışının belirlenmesinde kullanılabileceği görülmüştür.

- Geri dönüşümlü agrega oranının \%50'nin üzerinde olduğu yapısal elemanlarda, yapısal optimizasyonun anlamlı olarak elde edilebilmesi için minimum hacim değişim oranının arttırılması veya kiriş kapasitesini arttıracak önlemlerin alınması gerektiği belirlenmiştir.

- ITD hesap algoritmasının veya tasarım parametrelerinin $\% 50$ üzeri GDA içeren sürdürülebilir betonların karakteristik özelliklerini temsil edecek şekilde revize edilmesi gerektiği sonucu elde edilmiştir.

Elde edilen sonuçlar mevcut çalışma çerçevesinde geçerlidir. Daha genel ve kapsayıcı sonuçlar elde etmek için daha kapsamlı deneysel ve analitik çalışmaların yapılmasına ihtiyaç duyulacaktır.

\section{Kaynaklar}

[1] Gonçalves, P. and De Brito, J. Recycled aggregate concrete (RAC)-Comparative analysis of existing specifications. Mag. of Conc. Res., 62(5), 2010, 339-46.

[2] Rao, M.C., Bhattacharyya, S.M., Barai, S.V. Systematic approach of characterization and behaviour of recycled aggregate concrete. https://doi.org/10.1007/978-981-10-6686-3, 2019.

[3] Xiao, J. Recycled aggregate concrete structures. https://doi.org/10.1007/978-3-662-53987-3, 2018.

[4] Ritter W. Die Bauweise Hennebique (The Hennebique System). Schweizerische Bau-zeitung, Bd. XXXIII, 7, Zürich, 1899.

[5] Mörsch E. Der Eisenbetonbau, seine theorie und anwendung (reinforced concrete, theory and application). Stuttgart, 1902.

[6] Mörsch E. Concrete-steel construction. Goodrich EP, McGraw-Hill, New York, 1909.

[7] Querin, O.M., Steven, G.P. and Xie, Y.M. Evolutionary structural optimization (ESO) using a bidirectional algorithm. Eng. Comput., 15, 1998, 1031-48.

[8] Querin, O.M., Victoria, M., Diaz, C., Marti, P. Layout optimization of multi-material continuum structures with the isolines topology design method. Engineering Optimization, 2014.

[9] Querin, O.M., Victoria, M., Alonso, C., Ansola, R., Marti, P. Topology design methods for structural optimization. Elsevier Academic Press, eBook ISBN: 9780080999890, 2017.

[10] Victoria, M., Marti, P. and Querin, O.M. Topology design of two-dimensional continuum structures using isolines. Comput. Struct., 87, 2009, 101-9. 
[11] Victoria, M., Querin, O.M. and Marti, P. Topology design for multiple loading conditions of continuum structures using isolines and isosurfaces. Finite Elements in Analysis and Design 46, 2010, 229-237.

[12] Victoria, M., Querin, O.M., Marti, P. Generation of strut-and-tie models by topology design using different material properties in tension and compression. Struct. Multidisc. Optim., 44, 2011, 247-258.

[13] Victoria, M., Querin, O.M., Diaz, C., Marti, P. liteITD a MATLAB Graphical User Interface (GUI) program for topology design of continuum structures. Adv. in Eng. Softw., 100, 2016, 126-147 (https://www.upct.es/goe/software/liteITD_i.php).

[14] Saribas I. Stress-strain model for recycled aggregate concretes. El-Cezerî J of Sci and Eng 6(1), 2019, 156-165.

[15] Hognestad E. A study of combined bending and axial load in reinforced concrete members. University of Illinois Bulletin 49 no. 22, 1951.

[16] Turkiye Bina Deprem Yönetmeliği (TBDY 2018): Deprem Etkisi Altındaki Binaların Tasarımı için Esaslar. Ankara, Turkiye, 2018.

[17] Zheng, J., Zhen, L., Li, H., Jiang, C. Robust topology optimization for cellular composites with hybrid uncertainties. Int. J. Numer. Methods Eng., 2018, 1-19.

[18] Dewhurst, P. A general optimality criterion for combined strength and stiffness of dualmaterial-property structures. Int. J. Mech. Sci., 47, 2005, 293-302.

[19] Martin BT, Sanders DH. Verification and implementation of strut-and-tie model in LRFD bridge design specifications. American Association of State Highway and Transportation Officials, 2007.

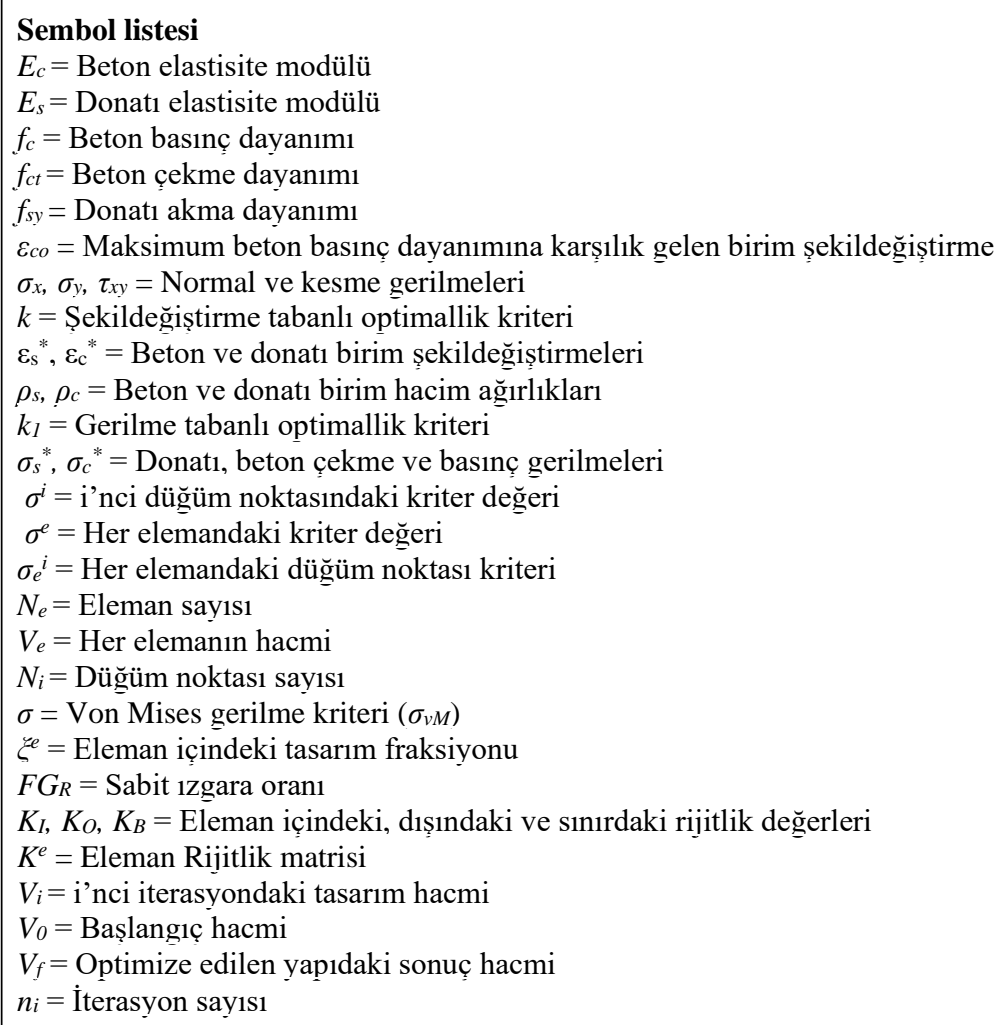

